\title{
ENKELE NOTITIES OVER HET OEVER-AAS VAN NIEUW GUINEA (EPHEM., PALINGENIIDAE)
}

\author{
DOOR \\ M. A. LIEFTINCK \\ Zoölogisch Museum, Buitenzorg, Java
}

Weinig onderzoekingen hebben in zo wijde kring bekendheid verworven als die van onze landgenoot Jan Swammerdam, die in zijn ,Ephemeri vita' (1675) en later in de ,Bybel der Natuur of Historie der insekten' (1737) de ontwikkelingsgeschiedenis beschreef van het beroemd geworden Oever-aas, Palingenia longicauda (Oliv.), de grootste palaearctische Ephemeride.

Dit allermerkwaardigst insect, dat - het zij terloops opgemerkt - reeds in I634 door de Amsterdamse medicus Augerius Clutius was beschreven en afgebeeld ${ }^{1}$ ), moet destijds in ons land alom de aandacht hebben getrokken wegens zijn massaal optreden gedurende een aantal warme dagen omstreeks het midden van de maand Juni. In Nederland echter is dit grote haft vermoedelijk reeds tegen het eind van de vorige eeuw uitgestorven. Thans leeft het nog in het stroomgebied der grote rivieren van Midden- en Oost-Europa (Oder, Weichsel en Wolga).

Zoals bekend is, zijn alle Palingeniidae, tot welke familie Swammerdam's haft gerekend wordt, in hun voorkomen strikt gebonden aan rivieren met langzaam stromend water en een slibrijke bodem. De larven leven ingegraven in de modder aan de oever van de rivier; zij zijn carnivoor en groeien slechts langzaam. $P$. longicauda heeft in Europa waarschijnlijk 3 jaar nodig om het tot volwassen insect te brengen. Over de ontwikkelingsduur bij andere soorten is helaas niets bekend.

De naam Eendagsvlieg is wel bij uitstek van toepassing op de leden dezer familie. Eén enkel individu van het gevleugelde haft leeft vermoedelijk niet langer dan luttele uren!

Dit volmaakt weerloze schepsel, zo opvallend door de ondoorschijnende, veelal melkwitte vleugels en lange staartdraden, heeft in Europa de naam "Oever-aas" ontvangen wegens het enorme aantal dode individuen, dat na

I) A. Clutius, 1634. De Hemerobio sive Ephemero insecto et. Majali verme. Amsterodami. 
het verschijnen van een massavlucht soms in aanspoelsel langs de rivieren wordt aangetroffen.

Zowel de paring als de bevruchting vinden plaats op het wateroppervlak, onmiddellijk na het uitkomen van de imago. In een bepaalde zwerm zijn de mannetjes doorgaans verre in de meerderheid en waarschijnlijk polygaam, terwijl volgens EATON één wijfje door meerdere mannetjes bevrucht kan worden.

Vrijwel onmiddellijk na de copulatie wordt de inhoud der ovariën van een bevrucht wijfje door vluchtige beroering van het wateroppervlak ,en masse” geloosd. Er zijn aanwijzingen dat dit bij voorkeur dicht bij de oever van de rivier geschiedt. De twee eierklompen vallen bij aanraking van het water aanstonds uiteen en de eieren zinken naar de bodem.

De belagers van deze grote haften zijn legio, doch twee factoren zijn voor de instandhouding der soort van veel betekenis: $\mathrm{I}^{\circ}$ haar massaal optreden, waardoor een relatief gering doch klaarblijkelijk voldoend aantal bevruchte wijfjes door de „mazen van het net der vernietiging" kan heenglippen, en $2^{\circ}$ het enorme aantal eieren dat één enkel indiv:du produceert.

Minder bekend is het feit, dat de familie der Palingeniïlae in een I4-tal soorten over een groot dee! van gematigd en tropisch Azië verspreid voorkomt. Haar vertegenwoordigers zijn zéér nauw aan elkaar verwant, en vertonen een overeenkomstige levenswijze, culminerend in een massaal optreden van de imagines op bepaalde tijdstippen. Dit neemt niet weg, dat de systematici, op grond van vrij aanzienlijke morphologische verschilpunten - inzonderheid het aderverloop der vleugels betreffende - reeds vijf genera hebben onderscheiden: Palingenia, met 3 soorten, bewoont centraal Europa tot Perzië; Anagenesia heeft met haar 8 vertegenwoordigers een uitgestrekt verspreidingsgebied in Azië; Mortogenesia, met slechts één soort, is beperkt tot een deel van Mesopotamië; terwijl tens'otte Plethogenesia en Tritogenesia, elk met één soort, van Nieuw Guinea bekend zijn geworden.

Het zijn de twee laatstgenoemde insecten, die mij aanleiding geven tot enkele notities van algemene aard, welke als inleiding zijn te beschouwen op een revisie van de in Nieuw Guinea voorkomende soorten dezer familie.

Tot nu toe kende men 2 soorten, Plethogenesia papuana (Eaton), uit het stroomgebied van de Fly-, en Tritogenesia bibisica Lest., van de Lorentzrivier, beide in Zuid Nieuw Gu:nea. Door de verschillende Nieuw Guineaexpedities uit latere tijd zijn ons echter nog 3 soorten bekend geworden, welke geen van alle met de beschrijving der bovengenoemde geheel overeenstemmen. Eén daarvan is afkomstig van de Mamberamo-delta, een tweede verder oostelijk, van de Tami-rivier, in de omgeving van de Humboldts-baai (beide aan de noondkust van het eiland), terwijt de derde soort werd gevonden aan de Omba-rivier (Argoeni-baai) in Z.W. Nieuw Guinea. Een $\sigma^{\top}$ van de twee laatstgenoemde soorten is op de foto afgebeeld. Op het bijgaande kaartje van het eiland zijn de verschillende vindplaatsen van al deze soorten ingetekend. 
Over de verschilpunten der papuaanse genera en soorten kan hier niet nader worden uitgewijd. De ver gevorderdé differentiatie dezer merkwaardige insecten op Nieuw Guinea is echter een punt dat alle aandacht verdient.

Wanneer men ean blik werpt op de photografieën der enorme delta's en de tot diep in het binnenland bevaarbare modderige rivieren van Nieuw Guinea, dan behoeft het niet te verwonderen dat het Oever-aas zich hier thuis gevoelt! En indien men op de kaart de loop dezer geweldige stromen volgt en hun onderlinge afstand berekent, krijgt men wel enige indruk van de bijkans onmetelijke uitgestrektheid, alsmede van het continentale karakter dat het

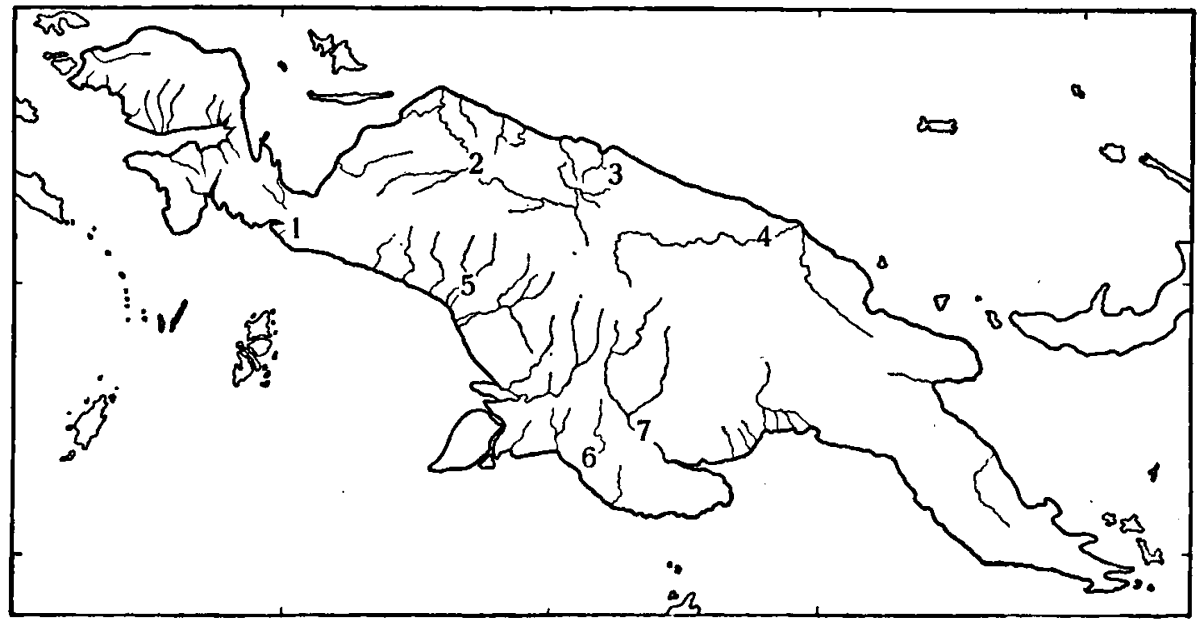

Kaart van Nieuw Guinea en omliggende eilanden, met het stroomgebied der grote rivieren. Bekende vindplaatsen van Palingeniidae genummerd. - I, Tritogenesia spec. (Omba rivier); 2, Plethogenesia spec. (Mamberamo-rivier en Meervlakte); 3, Plethogenesia spec. (Tami-rivier); 4, Palingeniide spec. (Sepik-rivier); 5, Tritogenesia bibisica Lest. (Lorentz-rivier); 6, Palingeniide spec. (Merauke rivier); 7, Plethogenesia papuana (Eat.) (Fly-rivier), Schaal I : 20.000.000.

mysterieuze ,,eiland” Nieuw Guinea draagt. Ook de onuitputtelijke rijkdom zijner fauna legt hiervan een steeds duidelijker getuigenis af!

Tot slot volgen hieronder enige literatuur-citaten van onderzoekers, die het voorrecht hadden het verschijnsel der "massa-vluchten" zelf waar te nemen. Interessant is, dat deze waarnemingen van het zwermen der verschillende soorten niet geheel met elkaar overeenstemmen. Waarschijnlijk zal wel blijken, dat elke soort zich gedurende haar ephemeer bestaan weer enigszins anders gedraagt. Nauwkeurige observaties aan de benedenloop der grote rivieren in de Oost-Indische archipel zouden van grote waarde zijn teneinde meer licht te werpen op een verschijnsel, dat ruim drie eeuwen geleden reeds door een Nederlands geleerde in ons eigen vaderland werd geboekstaafd! 
Mortogenesia mesopo:amica (Mort.), uit Mesopotamië.

K. J. Morton (Entomologist 54, 1921, 3).

Appeared on the Tigris in several spots in and about Amara on April I4th, 1918. They have not been noticed since. They did not fly in the air, but behaved like hydroplanes, circling and skimming over the surface of the water, the long "tails" dragging on the surface, the body slightly raised and the wings beating rapidly...... Amara, April 5th, 19I8. Large mayflies floating down stream in huge shoals for some days past; never seem to fly, though $\sigma^{\prime} \sigma^{\prime}$ (?) observed chasing $\$ Q$ (?) along the surface of the water, with much beating of inadequate wings. After that I never saw them fly, and they got more and more battered by the ripples on the surface of the water. Finished altogether in about a week from their first appearance.

Anagenesia robusta (Eaton), uit Assam.

F. H. Gravely (Rec. Ind. Mus. 18, 1920, 142).

Emerge annually at about the end of October, and for three or four days float down the river in countless millions. The natives say that they also appear on other rivers ...... and that they come out at and under the edge of the water in the shallows after the rivers have left the hills and where they run through silt only; but Mrs. Maxwell says that so far as she knows they do not occur on rivers actually rising in flat districts. The caudal appendages of the males were 3 inches long and semi-transparent when fresh. The insects are so light and hollow that they cannot be kept under water; when just out they are white and creamy and look like foam when blown together by the wind.

Anagenesia picta (Grav.), uit Koetai, E. Borneo.

H. Witkamp (Tijdschr. K.N.A.G. (2) 49, 1932, 53).

Op dit deel der Mahakam (zijrivier Benanga en Bahanas bij Merimoen) ziet men in den namiddag bij windstilte nu en dan een verschijnsel dat ook op de groote zijstroomen is waar te nemen, namelijk een ontelbaar aantal schoksgewijze over het water glijdende,.vuilgele en halfdoorschijnende haften (Koet.: kesoela), die in alle richtingen langs elkaar heenschieten, de twee achter-uitsteeksels wijd uiteengespreid. Komen ze in den golfslag van de boot, dan vliegen ze een oogenblik op om even verder hun onrustig schokkende beweging onverpoosd voort te zetten. Wel over een kilometer en meer kan het watervlak met deze door elkaar krioelende insecten bezet zijn.

Plethogenesia papuana (Eaton), Nieuw Guinea, vindpl. 7.

L. M. D'Albertis (in Eaton, Mon. Ephem. 1883, 28).

On the 2nd of July, I876, a few hours before sunset, we witnessed a strange and magnificent sight produced by an abundance of a species of Mayfly, 
actively pursued by the following birds:- Aplonis metallica, Artamus leucorhynchus leucopygialis, a Mino, a Eurystomus, and the commonest Whiteheaded Osprey, Haliastur indus girrenera ${ }^{1}$ ). Simultaneously the insects were being preyed upon by thousands of fishes, who rushed up to seize them whenever they touched the water with their delicate wings. But so profuse was the abundance of the flies, that the ravages of all their destroyers caused no appreciable diminution in their numbers. Mile after mile, from bank to bank, the river seemed covered with them, when all at once, as if by signal, the whole of them rose up confusedly, flying aloft in a thousand different directions, producing an effect in the air like that of a heavy fall of snow; then they descended again, and the snow seemed to cover the river with a white layer. The males very largely outnumbered the females.

Plethogenesia spec., Nieuw Guinea, vindpl. 2.

H. J. LaM .(Natuirk. Tijdschr. Ned. Indië, 88, 1928, 223-225).

Ik wil deze weinige opmerkingen over de fauna niet afsluiten zonder gerept te hebben van een der merkwaardigste natuurverschijnselen, die ik ooit bijwoonde: het zwermen der haften. Naar de lezer zal weten, zijn haften de imagines van neuroptere insecten van de familie der Ephemeriden. De larve leeft in verschillende stadia als roofinseci in het water, maar het imago, dat gedurende zijn ephemeer bestaan geen voedsel meer tot zich neemt, heeft u.tsluitend voor de voortplanting te zorgen. Is dit feit op zichzelf reeds merkwaardig genoeg, merkwaardiger nog is het gelijktijdig uitkomen van alle imagines op een bepaalde plek.

Haften zwermen op de groote rivieren in de lagere streken en herhaaldelijk waren we getuige van dit verschijnsel, dat zich nu eens in geringe, dan weer in sterke mate voordeed, eens in de twee of drie weken. De Meervlakte schijnt echter wel een bijzonder gunstig gebied voor deze dieren te zijn: nergens zagen we zulke machtige zwermen ervan als hier; en den grootsten indruk maakt dit natuurverschijnsel zeker op hem, die zulk een zwerm in zijń onmiddellijke omgeving ziet ontstaan en er het volgende oogenblik door omgeven is. Het was op een dag, dat ik terugkwam van de monding der Doormanrivier en, zachtjes met de koelies meepagaaiend, met de prauw naar het bivak voer. Wat slaperig door het vermoeiende werk van dien heelen morgen in het heete moeras, had ik mijn oogen half gesloten tegen het felle licht, dat wieerkaatste in het oppervlak van den glad en rimpelloos voortglijdenden stroom. Plotseling wordt mijn aandacht getrokken door een haft, die vlak bij het prauwboord heen en weer fladdert, een wit en lichtgeel, fijn diertje, dat haastig en met plotselinge wendingen zijn fijne sporen over het water trekt. Nog zonder vermoeden van wat er komen zal, kijk ik loom uit over de wijde, stille rivier,

I) De ter plaatse gebezigde nomenclatuur dezer vogels, is door de thans gebruikelijke vervangen. Hiervoor mijn dank aan Drs A. C. V. vaN BEMmel. 
totdat opeens mijn volle belangstelling is gewekt: een haft scheen zich, vlak bij mij, worstelend uit het water zelve los te maken. Hoewel ik nu met volle belangstelling en volle inspanning tracht waar te nemen, gelukt het mij niet den vollen omvang van wat er geschiedt te blijven volgen. Vlak bij tracht ik te zien, hoe de dieren uit het water opkomen en tevens wordt mijn oog getrokken naar zooveel andere punten, duizenden andere punten, waar hetzelfde geschiedt. En als ik een paar minuten later opkijk en de zooeven nog stille rivier overzie, is haar oppervlak reeds bezwermd door duizenden haften. Elke seconde komen er meer bij. Eerst na geruimen tijd van ingespannen turen gelukt het mij een haft te zien, die zich wringend uit de pophuid losmaakt en snel wegschiet, terwijl de ledige pophuid als een bijna onzichtbaar vliesje langzaam met den stroom mee drijft. Binnen zeer korten tijd het kan niet veel langer dan 5 minuten geweest zijn - is de gansche rivier overdekt met millioenen haften. Vele schieten over het water heen en weer 1 ), andere verheffen zich tot eenige meters boven het oppervlak en telkens ko-

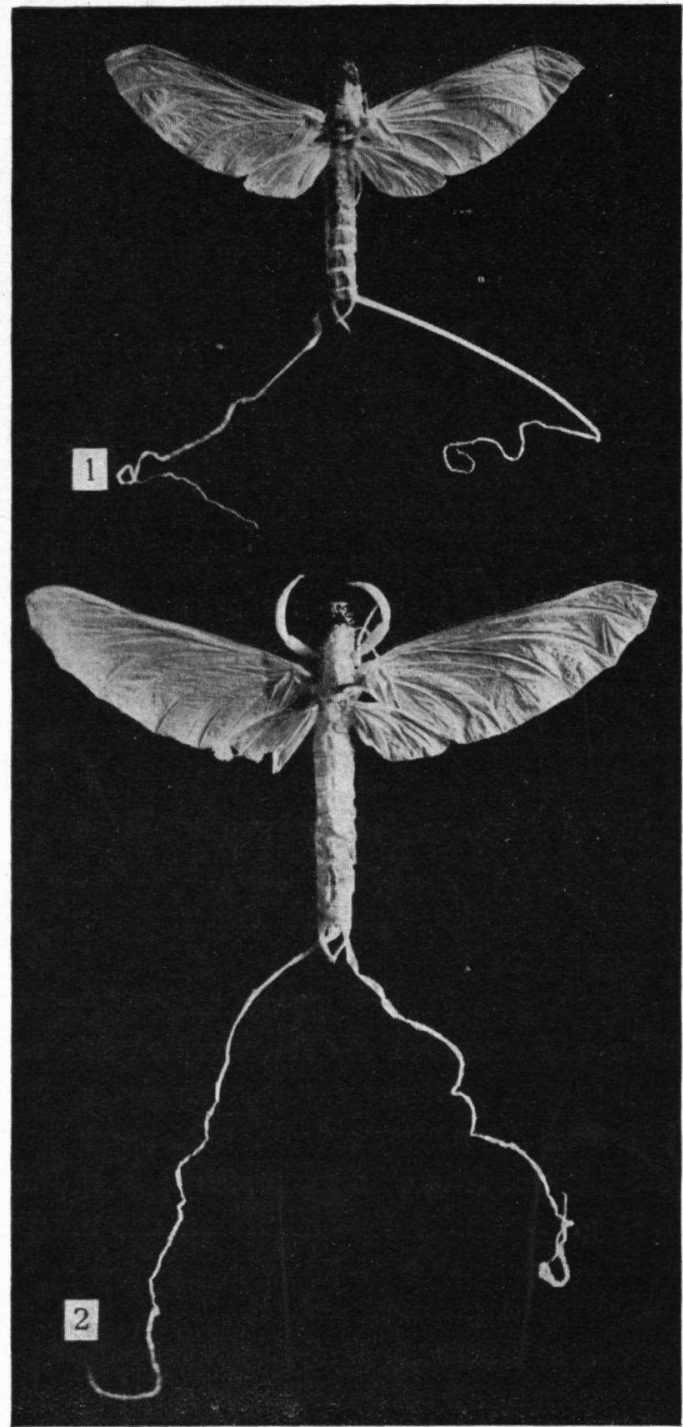

Fig. 1. Plethogenesia spec. \&, Tami rivier, 1-7. $\mathbf{x}$. 1936, W. Stüber (N. Nieuw Guinea, vindpl. 3). Fig. 2. Tritogenesia spec. of, Omba rivier, 28. vii. 1941, E. LundQvist (W. Nieuw Guinea, vindpl. 1). Beide $X_{I} 1 / 2$. Vleugelspanning onderste ex. $43 \mathrm{~mm}$. men er de prauw binnen vallen, zoodat die wat minder oppervlakkig kunnen

I) In zijn "Schets van flora en fauna van het Van Rees-gebergte rondom Albatrosbivak" (Mamberamo-vallei), spreekt DocTERS vAN LEEUWEN zeer toepasselijk van "witte haften die op de oppervlakte van het water tegen de stroom in voorttaxiën" (De Trop. Nat. I5, I926, 186). 
worden beschouwd. De mannelijke exemplaren bezitten tot copulatieorganen vervormde extremiteiten, waarmee zij de wijfjes schijnen te omvatten. Van het paren kon ik nagenoeg niets waarnemen; wel zag ik soms twee exemplaren in een kortstondige aanraking, maar ik kon niet uitmaken of dat werkelijk een copula was. Evenals bij Europeesche soorten, schijnen er ook hier onder duizenden mannetjes slechts enkele wijfjes voor te komen. Beide geslachten bezitten aan het achterlijf twee draadvormige aanhangsels - bij de mannelijke exemplaren veel langer dan bij de vrouwelijke - waarmede zij twee fijne sporen over het water trekken. Onder het laatste achterlijfssegment dragen de wijfjes twee peervormige eierzakjes, die bij aanraking gemakkelijk loslaten. Niet lang, eenige uren op zijn hoogst, blijft de zwerm op gelijke sterkte. In den beginne komen er nog telkens honderden exemplaren bij, maar allengs komen ook de vogels uit het bosch en uit de rietvelden en de visschen van den modderbodem aanzetten om zich aan dit onverwachte maal te goed te doen. Bijenetertjes en spitsvogeltjes schieten af en aan. Ik zie er, die, vermoeid van de jacht en reeds verzadigd, even uitrusten op een uit het water opstekende tak, maar die toch de verleiding niet kunnen weerstaan om zich nogmaals in den overvloed te werpen. Een ijle, donkere wolk van vogels warrelt door den dichten witten wolk van haften en de rose bekken der Siluriden komen happend telkens boven water. Om twaalf uur zag ik de eerste haft verschijnen. Om drie uur zijn ze alle verdwenen; waar zijn de exemplaren gebleven, die niet aan de eetlust van vogels en visschen ten of fer zijn gevallen en die de wind in het voor hen onherbergzame oeverbosch heeft neergesmeten?

Later, toen ik met het motorsloepje weer omlaag voer, ontmoette ik, eveneens omstreeks het midden van den dag, nog eens zulk een zwerm, maar nog veel groter. Van verre geleek de rivier als bedolven onder een sneeuwval van haften. Wij voeren meer dan een uur onafgebroken door die dichte zwerm, die dus een lengte had van minstens ${ }_{5} 5 \mathrm{~km}$ ! Een matige schatting (Io ex. per $\mathrm{m}^{3}$ ) geeft dan al een aantal van 120 millioen haften! 